\title{
Benefits and Limitations of the Built Environment's Work Integrated Learning in Undergraduate Education
}

\author{
J. Neoh ${ }^{1}$, C.C. Lee ${ }^{2}$ \\ ${ }^{1}$ Newcastle Australia Institute of Higher Education, Singapore. \\ juyang.neoh@uon.edu.au \\ ${ }^{2}$ School of Environmental and Life Sciences, Newcastle Australia Institute of Higher Education, Singapore. \\ charles.cc.lee@newcastle.edu.au
}

\section{Extended Abstract}

Work Integrated Learning (WIL) WIL has existed since the 1900s [1] and it is an important component in the Built Environment (BE) discipline education. WIL today is a vital part of student learning [2], it is a process where students are attached to a company for weeks or even months during or towards the end of their academic courses. WIL is an important component in the Built Environment (BE) discipline education. A BE is the human-made environment that provides the setting for human activity, ranging in scale from buildings to cities and beyond. It is the human-made space in which people live, work, and recreate on a day-to-day basis [3]. WIL is very important and beneficial to undergraduate students because the relevant knowledge, competencies and experiences can be acquired, even before they graduate and join the industry [4].

Considering the present-day challenges and complexities of the BE industry, there is an increased need for undergraduates who do not only possess a sound academic background, but also the necessary work experience. In light of leveraging students to handle the various challenging demands of the present-day BE competently, this paper discusses and compares the benefits and limitations of WIL with the students', universities' and employers' experiences. Recommendations were also given to overcome the limitations of WIL so that the WIL experience could be better for all the stakeholders.

This research study was carried out with reference to literature published in conference papers, government reports and journals articles in order to review the various benefits and limitations of WIL. The period of the document review was from the last 11 years: 2010 to 2021. This is to ensure that the data collected are relatively current. Data from all the sources were analysed using content analysis which is a research technique for systemically explaining the meaning of qualitative data. The aim of the result was achieved by revealing that there are some key benefits and limitations that are similar or in contrast with the various stakeholders.

An extensive literature search of 70 published articles found that the majority of them are from Australia and the United States. All the articles are related to the construction industry which includes Engineering, Construction Management, Architect and Quantity Surveying. After finding all the key benefits and limitations from various stakeholders' experience, comparisons were made, with those, we can clearly see that there are many differences between the various stakeholder's experience. As the saying goes, one man's treasure is another man's trash, what a person may consider a limitation to them could be a highly valued benefit to another person. Vice versa, a benefit for one person may be a major limitation for another person. This study will eventually contribute to a deeper understanding of the benefits and limitations of WIL from the students, universities and employers' perspectives. Such understanding and recommendations provided could lead to improvements in WIL, which is an important part of the built environment discipline. And given suggestions to improve on it. With that, it can be determined that this research has satisfied the research question.

\section{References}

[1] Weible, R. (2010). Are universities reaping the available benefits internship programs offer? Journal of Education for Business, 85(2), 1-5.

[2] Ojo, T. A. (2019). Work-Integrated learning practices: Lessons from private higher education institutions. Educor Multidisciplinary Journal, 3(1), 7-25. 
[3] Roof, K., M.S., \& Oleru, N., PhD. (2008). Public health: Seattle and king county's push for the built environment. Journal of Environmental Health, 71(1), 24-7.

[4] Lian, J. K., Foo, Z. Y., \& Ling, F. Y. Y. (2018). Value of internships for professional careers in the built environment sector in Singapore. Engineering, Construction and Architectural Management. 25(1), 7789. https://doi.org/10.1108/ECAM-09-2015-0133 